\title{
Understanding Problems of Vocational Counselling Information Seeking Behaviour in the Modern Nigeria
}

\author{
AGBAJE, A. A. ${ }^{1}$ and AGBAJE, A. O. ${ }^{2}$ \\ ${ }^{I}$ Department of Educational Foundations, Guidance and Counselling, University of Uyo, Uyo, Nigeria. \\ ${ }^{2}$ Union Bank of Nigeria Plc, Amuwo Odofin Branch, Festac, Lagos, Nigeria
}

\begin{abstract}
The study investigated the effects of career exploration intervention and career planning course on problems of Vocational Counselling Information - Seeking Behaviour of the Students in Uyo Metropolis. Two hundred and forty randomly selected senior secondary school class two students constituted the sample of the study. The sample consisted of 140 boys and 100 girls. Their age ranged between 15 and 18 years with a main age of 15.5 years and standard deviation of 0.66 years. Career Factor Inventory and Career Decision-making Self-Efficiency Scale were the two instruments employed in the study; data were analyzed using analysis of covariance and Duncan post-hoc measure. The results show that there were significant main effects of treatment on counselling information - seeking behaviour of the participants. The two treatments were also superior to the control groups on measure to counselling information-seeking behaviour of the participants and that career decision-making, self-efficiency and gender moderate the causal link between the treatments and the criterion measure. Based on the findings it was suggested that school counsellors and relevant stakeholders should making conscious effort to adopt career-planning course and career exploration intervention as tools for handling adolescents career-related concerns.
\end{abstract}

Keywords: Vocational Counselling, Information-Seeking Behaviour, Career Exploration Intervention, Career Planning Course.

\section{Introduction}

Vocational counselling is often used interchangeably with career counselling (Career Guidance or Career Education) eventhough the two terms do not necessarily mean the same thing. Vocational counselling, an oftshoot of vocational guidance movement, was the earlier term in use to describe information-giving and directive job counselling. With developing of innovative theories of vocational choice, however, the scope of vocational counselling soon become widened to include not only information-giving but also planning and making decisions about occupations and education. The use of the term "Career Guidance" (Career Education or Career Counselling) is thus to portray the true widened nature of the theme and in particular to emphasize the involvement of the "total person" in the process of choosing a career rather than on the single choice itself, (Belkin, 2004). It was further contended that career counselling touches upon the clients, "road life" role activities. It is not merely giving information on occupations as was originally conceived with the use of the term "Vocational Guidance" rather Career Counselling Interventions have ramifications in other areas of life functions Gibson, (Michel and Higglins, 2003) identifies that the use of the term "Career Guidance is to suggest the occurrence of certain experiences and understanding across the various life stages which have implications for building appropriate foundation for career planning and decision-making. Makinde and Alao (2007) noted that a few people still prefer to use the term Vocational Guidance because of its historical significance, it is however less descriptive if the field it is supposed to portray. The current trend in the use of the term "Career Guidance", is to better present the vast scope of activities that constitutes career intervention practice. This of course, is not to suggest that the role of information in career counselling is not important. School Guidance Programmes which fails to profile youth with information or basic knowledge and opportunity for learning about their environment and themselves short-change youth, (Shertzer and Stone 2004). Career guidance comprises not only information about occupations but also several other factors about individuals all of which play very vital roles in career decision making and choice.

An important feature of Career Guidance practice is the fact that it incorporates all the different aspects of Counselling and Guidance including the group approach, the information-giving services, the interaction between counsellor and client, evaluation and appraisal function, that is, career guidance is very much like other types of guidance and this is why it is being described as a unified approach and as integrated efforts in what have otherwise traditionally been termed educational and vocational counselling (Belkin, 2004). The term Educational and Vocational Guidance which is currently being subsumed under Career Guidance is used to describe specialized types of counselling applications designed to provide information and psychological assistance which may directly affect he decision and choice the client is about to make with respect to schooling 
immediate employment and future job directions. To further emphasize the multi-disciplinary nature of Career Guidance and in particular in an effort to make it more applicable to the school setting, (where most Career Guidance actually take place), (Shertzer and Stone, 1974) described Educational and Vocational Guidance as continuous help given to students/clients in school and outside school to enable them understand themselves better, their assets and limitations so that they may progress successfully, respond to the new demands and use their capabilities to the fullest potential in their world of work. Thus Career Guidance involves adequate and appropriate knowledge of oneself including insight into one's interests, abilities, aptitudes, values and attitudes all within the framework of work. Besides, information and factual data are still very significant and even more in Career Guidance that in Personal Guidance (Tolbert, 2002). This nature of Career Guidance makes it inseparable from other types of Guidance (Educational and Personal) Achebe (2002), for instance, noted that help given to students to choose their subjects and adjust to school life, Educational Guidance, is closely related to personal and vocational adjustment. Belkin (2004) noted that it is usually not possible to help someone with a vocational problem without recognizing such other aspects of his life as students, conflicts and relations which others. In the same vain, (Mathewson, 1962) also observed that genuine Vocational Guidance not only involves Educational Guidance but also personal motivations and values as well as behaviour disposition. No doubt, long standing personal problems will militate against high educational achievement which in turn will determine the range of occupations an individual may enter, (Jaskson and Jumper, 2001).

The definitions of the two generic terms of career and occupations not only help to distinguish between the two terms but further help to appreciate the wider scope of Career Guidance. Super and Bohn (1990) noted that career is the sequence of occupations, job positions engaged in or occupied throughout the life time of a person. A career as defined by Isaacson (1971) is the way in which the individual expresses himself and related to society through work. With these definitions clearly show that career is the totality of one's experiences in the world of work (Makinde and Alao, 2007). This further goes to explain why studies on career normally focus on cumulative experiences of workers in their life-long involvement with work. This is not so with occupation which according to Shartle (1959) is a term used to refer to a group of similar jobs in various establishments.

One other feature of Career Guidance which we need to consider in respect of the scope of the subject matter is the totality of the functions which a Vocational or Career Counsellor is called upon to perform in a career counselling process. According to Belkin, (2004), when a client comes for vocational counselling the counsellor's total efforts during the process may be grouped into the following three main categories:

- Identification of the client's vocational interest and abilities. This may be accompanied by an interview or may require the administration of vocational interest and aptitude inventories;

- $\quad$ Provision of assistance to client in learning how to increase his vocational skills, aiming toward levels of competency necessary for success in the job market; and

- $\quad$ Provision of assistance to the client in dealing with his feelings about work. This may include persistent feeling of frustration in finding the right job, difficulties at work, feelings of hopelessness that preclude looking for work.

The nature of the scope of the functions also shows that career guidance is an organized systematic programe offered to help the students develop self-understanding, understanding of societal roles and knowledge about the world of work. The career counsellor functions also included assistance with the development of decision making skills and the framing of occupational and educational plans. In essence therefore Career Guidance process goes far beyond the choice making process to include the process of planning, decision-making and implementation of decision. This analysis of Career Counselling also shows that it is a synthesis of different counselling skills directed toward helping clients explore occupational possibilities and to make satisfactory decisions and choices.

\section{Problems of Career Guidance}

Gibson, Michel Higglins (2003) revealed that most secondary school graduates encounter problems when moving from secondary school to higher institutions and from school to work due to lack of relevant information about occupations, lack of personal and educational requirement to progress in job, scarcity and misdistribution of job opportunities. Students have been formed to select occupations because of positions and prestige attached to the jobs having no regard to their interests and abilities and the relationship between these and selected occupations. Some of the problems one may readily forces from the consideration of the nature and characteristics of Career Guidance may be stated as follows:

- $\quad$ Lack of understanding of the scope of Career Guidance;

- $\quad$ Lack of understanding of the developmental stage at which Career Guidance intervention should occur;

- $\quad$ Lack of understanding of the type of information needed for Career Guidance;

- $\quad$ Lack of understanding of the appropriate skills to use in collecting relevant career information;

- Inappropriate information dissemination strategies. 
These factors contribute greatly to the wastage of human resources as well as misplacement of interest. When students make unrealistic career choices frustration, lack of interest, apathy to work and misuse of talents could be the bad result. A result from National Centre for Education Statistics, (2004) in the United States discovered that most career decision-making of adolescent is unintentional and uniformed $45 \%$ of high school students said that they have never received meaningful Career guidance at school. $65 \%$ of 11 thand $12^{\text {th }}$ graders never had a one-on-one meeting with their school counsellor to discuss post-secondary and Career opportunities. $78 \%$ of students credit their parents as the top adult influence regarding career planning and $65 \%$ of working adult do not believe that they are in the right jobs. If this is the true situation in a highly civilized and developed society, then what would be the story in the developing world? Therefore improving career guidance through information-seeking behaviour of adolescents is the major problem being addressed in this study.

To alleviate these career problems, career exploration activities would also provide students with better understanding of the changing nature of careers due to technological advances, the impact of global economy and the anticipation of the need for individuals to change careers several times during the course of a life-time, (Balkin, 2004). During the past three decades, several researchers have focused on the nature and contexts of career exploration, encouraging career development professional to increase their understanding of the career exploration process across life-span and for diverse population, (Makinde, 2007).

Career planning course which is an intervention that builds students career related to knowledge through engagement with a structured classroom curriculum, regardless of its credit beating status. Achebe, (2002) identified the following goals of career planning course;

- $\quad$ Increase the students knowledge about themselves, their interests, abilities, needs and values;

- $\quad$ Develop positive work attitude;

- Increase their knowledge of career possibilities, the structure of the world of work and job duties and requirements;

- $\quad$ Point out the implications of career and self-knowledge of career possibilities;

- $\quad$ Teach principles of decision-making and planning skills;

- Improve skills in seeking, creating, evaluation and communicating vocational information;

- $\quad$ Develop job-seeking skills and

- Motivate and students to attend school regularly.

The effectiveness of career planning course are well documented in research literature. For example, Makinde and Alao (2007) using both developmental and experimental instructional techniques to increase learning about careers in psychology found their students in the career course in comparison to students in another psychology course and a communication course indicated greater comfortability with their career decision-making situation more certainly about their career choices. The results show that the approach was more effective than the comparison group in enhancing career decision-making self efficacy of students. The study also explored the influence of career self-efficacy and gender on the career information-seeking behaviour by using them as moderating variables.

Self-efficacy as conceptualized by Bandura (1977) has to do with the amount of confidence a person has in him or herself in carrying out a designated task. It is not an empty boasting but rather confidence backedup with knowledge and skills to execute a particular programme of action. Self-efficacy made in-road into career literature through the scholarly works of (Johnson and Juniper, 1991). It was empirically revealed that self-efficacy influences the career decision, achievement and adjustment behaviours of men and women. Subsequently researchers (Gibson, Michel and Higglins 2003, Makinde and Alao, 2007) have further established the crucial role of self-efficacy in person's choice of activities, vocational interest, career maturity, effort expenditure and persistence. In the present study, self-efficacy is employed as a moderating variable. The essence was to see if self-efficacy would moderate the relationship between treatments and the criterion measure.

\section{Purpose of Study}

Considering the centrality of the problems of vocational counselling, a viable programme of career counselling would really help the students to develop an awareness of themselves in relation to the world of work through unbiased career information. Besides, the students should be able to gather information about themselves and occupations, estimate the problems outcome of various course of study they take school and finally choose alternatives that are attractive and possible for themselves by using Career Exploration Intervention (CEI) and Career Planning Course (CPC).

\section{Hypotheses}

Based on the objectives of this study, the following hypotheses were tested at 0.05 Alpha level: 
- There is no significant difference in the occupational information-seeking behaviour scores of participants treated with career-exploration intervention and career planning course and the control group.

- There is no significant difference in the career information -seeking behaviour scores of participants treated with career-exploration intervention and the control group.

- There is no significant difference in these career information-seeking behaviour scores of participants treated with career planning course techniques and the control group.

\section{Design}

The researchers utilized pre-test-post-pest control group quasi experimental design with 3 x 2 x 3 factorial matrix. There were two treatment programmes and the control group in the row. The column has gender varying at two-levels and career decision-making self-efficacy categorized as high, moderate and low.

\section{Participants}

A sample of 240 participants were involved in this study. They were randomly drawn from three public co-educational secondary schools in Uyo. Both sexes are equally represented in the study. Each of these three schools has a sample size of eighty (80) participants, forty (40) males and forty (40) females respectively. The participants were senior secondary class two students because they have had enough experience in determining their choice of career. Their age ranged between 14 and 18 years with a mean age of 14.8 years and standard deviation of 0.58 years. All the participants in the two experimental groups participated fully in the training programmes but those in the control group were not given any treatment. The group that received treatments were compared with the control group to test for treatment effects.

\section{Instrumentation}

Two instruments were implored in this study, they are; Career Factors Inventory (CFI) and DecisionMaking Self-Efficacy Scale. Career Factors Inventory was developed by Johnson and Juniper (1991). It is a four factors inventory with a total of 44 items. The need for Career information and need for self-knowledge subscales which represent information factors were utilized for the study. Typical items on the subscales are (1) Before choosing or entering a particular career are, "I still need to talk to people in one or more various careers", (2) "Before choosing or entering a particular career area, I still need to attempt to answer who am I". The response format of the scale ranges from strongly agree to strongly disagree. The two subscales have a total of eleven items. The whole instrument has a test-re-test reliability values ranging between .79 and .84 and a Crobach Alpha index of between .73 and .86. The internal consistency for the total inventory was .87 .

As specified by the authors, a client's CFI profile configuration might suggest specific intervention for enhancing career information seeking behaviour. This suggestion provides the rationale for adopting the scale for the use in this study. The second scale used in this study is Career Decision Making Self-Efficacy Scale (CDMSES) developed by Achebe, (2002). The instrument has five subscales, namely (a) self-appraisal (b) occupational information (c) making plans (d) problems solving and (e) goal-setting. It has a total of thirty eight items with response format ranging from, not sure (1) to very much sure (5). The instrument has a theoretical values of between 38 and 190. The self-appraisal subscale has a total of nine items with a co-efficient Alpha of .75. Occupational information subscale has eleven items 9.85). problem solving subscale has six items (.77) making plans subscale also has six items (.85) and goal-setting subscale has five items (.77). The overall scale has a Crobach Alpha value of (.79). The instrument was used to identify levels of self-efficacy of the participants.

\section{Procedures}

Having interacted and secured the permission of the school authority, students were addressed at the assembly arena. The focus of the speech was on the understanding problems of vocational counselling. Sequel to this, interested students were asked to indicate their willingness to participate in the programme. Ballot method, a kind of random sampling technique was used to select the participants for the study. Later the participants were randomly assigned to their experimental and control groups.

The study was carried out over a period of nine weeks in three different schools in Uyo Metropolis. The training scheduled was only once a week and each session only lasted for an hour. Two schools served as experimental groups while the remaining school was used as control group. Two instruments namely: Career Factor Inventory and Career Self-Efficacy Scale were administered to the participants as pre-test. The career self-efficacy scale was administered to the participants to ascertain their levels of self-efficacy. Career factor inventory was also used as post-test.

The experimental group one was exposed to career-exploration intervention training while experimental group two was treated with career-planning course. Thus the control group was not treated but was 
given a brief study skill counselling after the post-test. A post-test in career factory inventory was also administered to the three groups.

\section{Data Analysis}

Analysis of co-variance (ANCOVA) was used to analyse data. It was so used because of its capacity to take care of the initial differences among the participants.

\section{Results}

The result of data analysis for the hypothesis which stated that there is no significant difference in the problems of vocational counselling information seeking behaviour scores of participants treated with CareerExploration Intervention (CEI) and Career-Planning Course (CPC) and control group is presented below.

Table 1:Analysis of Co-variance (ANCOVA) on Problems of Vocational Counselling Information Seeking Behaviour of the Experimental Participants and Control Group

\begin{tabular}{|c|c|c|c|c|c|c|}
\hline Variable & Source & $\begin{array}{ll}\text { Sum } & \text { of } \\
\text { Square }\end{array}$ & df & Mean & $\mathbf{F}$ & $\mathbf{P}$ \\
\hline Counselling & Row & 742.94 & 2 & 371.47 & 1225.42 & $<.05$ \\
\hline Information & Columns & 18.71 & 2 & 9.35 & 30.86 & $<.05$ \\
\hline Behaviour & Within & 1036.73 & 171 & .303 & & \\
\hline
\end{tabular}

As stipulated in Table 1, the analysis of co-variance of participants post-test-scores on counselling information seeking behaviour shows that there is significant main effect of treatment $(\mathrm{F} 1,114=2443.67, \mathrm{P}<$ 0.05). Consequently, the null hypothesis which postulated that there will be no significant difference in the counselling information seeking behaviour of the experimental participants and the control group was rejected. The inference that could be drawn from this result is that significant difference existed in the counselling information seeking behaviour of treated participants and the control group. It is also noted that there is moderating effect of gender and self-efficacy on participants counselling information seeking behaviour ( $\mathrm{F} 2$, $171=30.86, \mathrm{P}<0.05)$. The interacter of gender and self-efficacy was also significant $(\mathrm{F} 4,171=4.85, \mathrm{P}<$ $0.05)$.

Table 2: Analysis of Co-variance (ANCOVA) Showing the Effect of Career Exploration Intervention Adolescent Counselling Information Seeking Behaviour

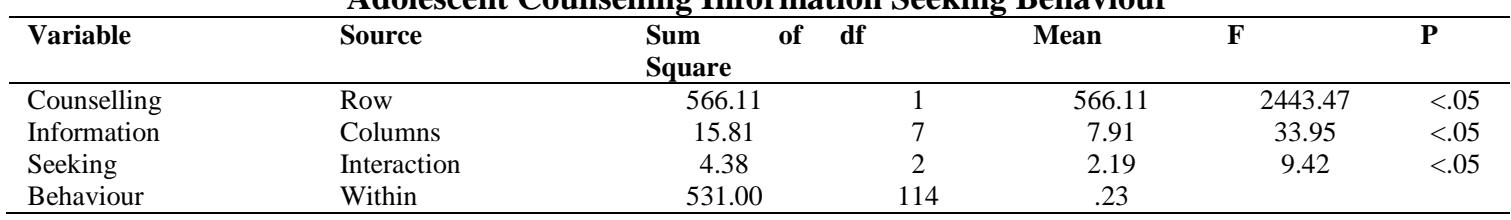

The result in Table 2 shows that there was significant effect of career exploration intervention on the counselling information seeking behaviour of the participants $(\mathrm{F} 1,114=2443.67, \mathrm{P}<0.05)$. As a result, it is concluded that career exploration intervention was superior to the control group. Besides, both gender and career self-efficacy influence the relationship between the causal variable and the criterion measure (F2, $114=$ $33.95, \mathrm{P}<0.05)$. There was also significant interaction effects of rows and columns $(\mathrm{F} 2,114=19.42, \mathrm{P}<0.05)$.

Table 3:Analysis of Co-variance (ANCOVA) Showing the Effect of Career Planning (CPC) Course on Adolescent Counselling Information Seek Behaviour

\begin{tabular}{llcccc}
\hline Variable & Source & $\begin{array}{l}\text { Sum of } \\
\text { Square }\end{array}$ & df & Mean & F \\
\hline Counselling & Row & 543.10 & 1 & 543.10 & 2060.93 \\
Information & Columns & 6.71 & 2 & 3.35 & 12.74 \\
Seeking & Interaction & 4.28 & 2 & 2.14 & $<.05$ \\
Behaviour & Within & 600.83 & 114 & .76 & $<.05$ \\
\hline
\end{tabular}

As shown in Table 3, there was significant difference in the counselling information seeking behaviour scores of participants exposed to career planning course and the control group $(F 2,114=2060.93, \mathrm{P}<0.05)$. This shows that career planning course was effective in fostering counselling information-seeking behaviour of the participants. Besides, gender and career self-efficacy moderate the relationship between treatment and the criterion measure $(\mathrm{F} 2,114=2.74, \mathrm{P}<0.05)$. There was also significant interaction effect of treatment and columns $(\mathrm{F} 2,114=8.13, \mathrm{P}<0.05)$. 
Table 4: Multiple Classification Analysis (MCA) of Counselling Information Seeking Behaviour Scores by Level, Treatment and Gender Grand Mean = 28.49

\begin{tabular}{lcccc}
\hline Variable + Category & $\mathbf{N}$ & $\begin{array}{c}\text { Unadjusted } \\
\text { Deviation }\end{array}$ & $\begin{array}{c}\text { ETA } \\
\text { Levels }\end{array} \quad$ Bdjusted Force Variance \\
Deviation
\end{tabular}

Table 4 shows Multiple Classification Analysis (MCA) of the adjusted independent variables plus the co-variable. The adjusted deviation value of 6.52 is an indication of the effectiveness of career exploration intervention in enhancing Counselling Information Seeking Behaviur of the participants. Career exploration intervention demonstrated superiority over career planning course and control group with adjusted deviation value of 6.34 and -12.86 respectively. Nonetheless career planning course was effective in fostering counselling information-seeking of the participants when compared with the control group. The MCA also indicates that there was high degree of correlation between counselling information-seeking behaviour and the treatment as evident by the multiple $\mathrm{R}^{2}$ value of .959 . By implication $95.9 \%$ of the variance of the criterion variable (Counselling Information Seeking Behaviour) is attributable to career exploration intervention and career planning course.

Table 5:Dimcan Multiple Range Comparison of Treatment Groups Means Score on Counselling Information Seeking

\begin{tabular}{|c|c|c|c|c|}
\hline Mean & Group & Treatment Control & Group CPC & CEI \\
\hline 22.1333 & Control & & & \\
\hline 29.1333 & $\mathrm{CPC}$ & $* *$ & $* *$ & \\
\hline 34.2000 & CEI & $* *$ & $* *$ & \\
\hline
\end{tabular}

Key ** pairs of Groups significantly different at $P<.05$.

Dimcan post-hoc analysis procedures were further carried out on the result in order to find out where the significant effect lies. The result presented in Table 5 shows that the experimental group 1 (CEI) is significantly different from experiment (CPC). While experiment 11 (CPC) is statistically significantly different from experimental group 111 (Control). Therefore, the CEI group is superior to both CPC and control groups. Likewise, CPC group is superior to Control Group, that is, CEI > CPC > control group on the counselling information-seeking behaviour mean score.

\section{Discussion}

The participants in the treatment groups scored significantly higher on measure of counselling information-seeking behaviour than their counterpart in the control group. Both CEI and CPC counterpart in the control group. Both CEI and CPC were effective in enhancing the participants counselling information seeking behaviour. This finding corroborates the assertion of Achebe (2002) that career exploration has a positive impact on the decision making process, in job search, placement and on counselling placement and attainment. It also concurs with that of Hoppock 1974 who posited that career exploration predicts the competence to generate career options and that it is a significant predictor of career decision-making.

One possible explanation for the effectiveness of (CEI) in improving counsellig information-seeking behaviour of adolescent is that it exposes the participants to various avenues through which they could seek for counselling information. Besides, the method widens their knowledge on various available counselling/career existing in the society and beyond.

Besides, the effectiveness of CPC could be attributed to the fact that it was presented as another interesting school subject which is characterized by good-teacher-student interaction where all participants were free to express their opinions, had their misconceptions corrected or clarified and new information was given to broaden their knowledge about what their planning is all about. The effectiveness of CPC in enhancing counselling information-seeking behaviour was supported by the study of Isaacson (1971) who discovered that 
high school students who took CPC had less career-related indecision at the end of the course than the comparison group.

The result of the second hypothesis indicates clearly that there existed significant difference in the counselling information-seeking behavior of CEI participants and the control group. This result attested to the effectiveness of the treatment programme. The finding is in line with the previous studies of Okon, (2007) and Olayinka (2004) that concluded that vocational exploration produces favourable results in terms of career development, mainly when individuals explore significant and useful information in relation to their proximal career development task. This finding is also in agreement with Makinde and Alao (2007) who asserted that career-exploration has a significant impact in vocational maturity and self-concept crystallization. They further explained that career exploration has an impact on the decision-making process, in job search, and placement and on occasion satisfaction and attainment. It would have been a greater surprise had the control participants performed better than those participants treated with CEI since it had been confirmed in the first hypothesis that the two treatment strategies were superior to the control group. However the low performance of the control participants was due to the fact that they were not exposed to any treatment.

The third hypothesis further proved that there was a significant difference in the counselling information-seeking behaviour scores of the participants exposed to CPC when compared to those in control group. The significant difference is rooted in the fact that the treated participants were exposed to a comprehensive CPC treatment programme. The control group on the other hand was not exposed to any form of treatment. The finding corroborates the assertion of Gibson, Michel and Higglins (2003) who established that counselling training programme could be effective in broaden the counselling outlook as well as improving the vocational maturity of students. The finding was also supported by Belkin (2004) who discovered that high school students exposed to career-enhancement treatment performed better that the comparison group on careerrelated indecision problems.

One other important aspect of the present study is the moderating influence of career self-efficacy and gender on the casual link between the intervention programmes and the criterion measures. Self-efficacy has been established as a critical factor in career decision-making process and its influence was reported to be stronger than that of interest, Tolbert, (2002), Strebalms, Marinelli and Messing (2002). In making careerdecision, series of task are involved and the appropriateness of such decision would to a large extent be influenced by the extent to which a person believes in himself or herself to execute relevant vocational task. This explanation probably holds for participants in this study. The interaction effects of gender on the treatment outcome is a validation of the general notion that gender plays a crucial role in career behaviour. The preponderance of evidence in literature (Peterson and Park, 1999) is either that males are better than the females in certain counselling task or vice-versa. Occupation stereotyping is indeed a common feature in career literature and at a large extent in counselling task. The present finding is therefore an affirmation of the influence of gender on vocational behaviour.

\section{Conclusion}

For the proper implementation of CEI and CPC, career counselling and teachers should consider the duration of the training, it should not be too long to avoid boredom and similarity it should not be too short so that some essential points would not be omitted or hastily taught to the extent that the students will benefit little or nothing from the training. Each of the techniques should be taught step by step and each training session should be loaded and vital points thoroughly explained.

This study has shown us the criticality of self-efficacy in career decision process. Thus it is therefore important for school counselling psychologists to develop intervention programmes to enhance career decisionmaking and self-efficacy of students. Variable career counselling programme can ill-afford to ignore the role of self-efficiency in career development process. Although occupational stereotyping is gradually wanning, gender for a very long time to come would still be an issue in career decision-making and career counselling generally. Counselling psychologist would course need to be gender sensitive in the course of performing their professional duties.

\section{References}

[1]. Achebe, C. C. (2002). Techniques of Educational and Vocational Planning. In T. Ipaye (Ed.) Educational and Vocational Guidance: Concepts and Approaches, Ile-Ife: Obafemi Awolowo University, Ife Press Ltd.

[2]. Bandma, A. (1977). Self-efficacy: Towards a Unifying Theory of Behavioural Change. Psychological Review, 84, $191-215$.

[3]. Belkin, G. S. (2004). Introduction to Counselling. ( $2^{\text {nd }}$ Ed.) W. M. C. Brown Company Publishers.

[4]. Federal Republic of Nigeria (2001). National Policy on Education, Abuja Federal Government Press

[5]. Gibson, R. L., Michel, M. H. \& Higglins, R. E. (2003). Development and Management of Counselling Programmes and Guidance Service, New York: Macmillan Publishing Co. Inc.

[6]. Hoppock, R. (1974). Occupational Information, New York. McGraw-Hill

[7]. Isaacson, P. (1971). Career Information in Counselling and Teaching, Bostons Allyn and Bacon.

[8]. Johnson, R. A. \& Jupiter, B. F. (1991). A Manual of Educational Guidance. Holt, Renehart and Winston. 
[9]. Makinde, O. \& Alao, K. (2007). Profile Career Education, Ibadan: Signal Educational Services Ltd.

[10]. Mathewson, R. H. (1962). Guidance Policy and Practice. New York: Harper and Row Publishers.

[11]. Okon, S. E. (2007). Secondary School Education and Employment in Nigeria: Implementations for Career Guidance: A Study of the River State, Nigeria. Columbia Teachers College, University Microfilms, No.88 - 22-282.

[12]. Olayinka, M. S. (2004). Choosing a Career in a Modern Age. Daily Times, Lagos, Nigeria, November $14^{\text {th }}$.

[13]. Peterson, J. K. and Park, D. (1999). Values in Career Education, Some Pitfalls. Phi Delta Kappan 56(a).

[14]. Shaette, C. L. (1959). Occupational Information: Its Development and Application. Englewood Cliffs, N. J. Practice Hall.

[15]. Shertzer, S. and Stone, B. (1974, and 2004). Fundamentals of Guidance and Counselling, Boston: Houghton Mifflin Company.

[16]. Strebbalms, D. J., Marinelli, R. P. \& Messing, J. P. (2002). Career Development: Concepts and Procedures. Monterey, CA: Brooks/Cole.

[17]. Tolbert, E. L. (2002). An Introduction to Guidance: The Professional Counsellor. Boston Little, Brown and Company. 